\title{
DESENVOLVIMENTO CONTINUADO DE PROFESSORES DE LÍNGUAS NO CIBERESPAÇO
}

\author{
Tânia Maria Moreira \\ taniamoreirabr@yahoo.com.br \\ Rosangela Segala de Souza \\ rosangela_s@hotmail.com
}

\section{RESUMO}

Neste artigo pretendemos apresentar as tendências em termos de modelos de formação de professores a distância, identificar como têm sido utilizadas as ferramentas tecnológicas em tal modalidade e explicitar algumas reflexões teóricas sobre um modelo holístico de formação continuada de professores de línguas on-line.

\section{INTRODUÇÃO}

Escrever sobre formação continuada constitui-se em um imenso desafio, porque podemos investigar os modelos e teorias, dentro de uma linha sócio-interacionista sobre a formação presencial e a distância, analisar a legislação e a regulamentação dessas modalidades de formação e estudar as práticas implementadas com enfoque nos atores de aprendizagem a partir de experiências reais em diferentes contextos sociais.

No desenvolvimento de ações orientadas para a reflexão e mudanças de concepções de professores de línguas, torna-se importante a compreensão de algumas concepções teóricas básicas e a identificação das ferramentas empregadas nesse processo para, então, optarmos por uma abordagem teórica mais coerente com a proposta de desenvolvimento de habilidades e competências compatíveis com as necessidades sócio-culturais e educacionais em um grupo professores.

\section{MODELOS E MEIOS USADOS NA FORMAÇÃO E DESENVOLVIMENTO DE PROFESSORES}

$\mathrm{Na}$ formação de docentes, tanto em situação de aprendizagem presencial quanto a distância, alguns estudos apontam duas tendências semelhantes em termos de modelo pedagógico e mencionam como as ferramentas tecnológicas têm sido usadas. 
É importante lembrar, antes de nos referirmos às tendências de formação de docentes, que nenhum tipo de conhecimento se processa independente do uso de tecnologias intelectuais, como o quadro, giz, a fala do professor, mimeógrafo, xerox, a $\mathrm{TV}$, o rádio, o vídeo cassete, o gravador, o retroprojetor, o computador. Os usos previstos desses recursos, nos programas de formação continuada, estão relacionados com o modelo teórico de formação de professores adotado. Conforme Magdalena \& Costa (2003), esses recursos determinam não só o alcance da disseminação das informações disponíveis em diferentes épocas, o suporte em que ficam registradas (de modo mais ou menos efetivo), como também instituem relações de poder entre o "emissor" e os "receptores" das informações.

Com relação aos modelos de formação, na primeira vertente a educação é concebida como um instrumento destinado a adequar o futuro profissional ao mundo do trabalho, disciplinando-o e provendo-o de saberes técnicos visando a facilitar a assimilação de informações para que os professores possam "ascender na vida", inserir-se de forma vantajosa no mundo existente. Para garantir uma inserção e assegurar reconhecimento e remuneração, ou seja, o "sucesso", o professor é concebido, conforme Gómez (1995), como um técnico especialista. Nesse modelo, ele recebe de forma passiva, para tão-somente "aplicar", teorias e preceitos formulados por pesquisadores e especialistas, seja pelos meios de comunicação de um-para-muitos (TV, rádio, material impresso, computador), seja pelos meios de um-para-um (telefone, correios), como uma via de mão única (Azevedo, 2002).

Segundo Azevedo (idem), dentro do modelo de formação do profissional técnico especialista, na Internet, freqüentemente,

(...) tem sido suficiente substituir o material impresso, a TV ou o rádio pela página web e suas potencialidades multimídia, e/ou o telefone ou o serviço postal pelo correio eletrônico ou o chat. Portanto, para desenvolver um curso online dentro deste modelo, podem ser suficientes bons recursos que permitam a disponibilização de material em formatos diversos (texto, imagem, áudio e vídeo) e a comunicação um a um entre aluno e professor ou aluno e tutor. Se a estes recursos se puder associar dispositivos que permitam medir a assimilação de informações e rastrear o acesso do aluno ao material, identificando se e quanto tempo ele aplicou à visualização de páginas web do curso, tem-se então um conjunto que satisfaz plenamente. (...) Recursos que permitam a interação coletiva podem ser também adotados, mas de forma claramente secundária e acessória. 
$\mathrm{Na}$ segunda visão de formação de professores, é assegurada uma autonomia ao professor na sua esfera de atuação. A educação centra-se na formação de valores humanos do cidadão, na sua visão crítica e criativa para profissionalizar o professor. Gómez (idem) situa, nessa modalidade, o professor como um prático autônomo, um profissional, que (re)descobre os conhecimentos na sua complexidade, identifica e analisa situações problemáticas, opta por decisões estratégicas e técnicas escolhendo com ética os meios e instrumentos mais adequados aos objetivos da situação, e por fim avalia de maneira crítica suas ações e os resultados, retroagindo para reformular estratégias e premissas continuamente.

Esse modelo parte do pressuposto de que a interação dialógica de muitos com muitos constitui a essência do processo educativo. Por esse motivo, as atividades que conduzem à aprendizagem são pautadas, nesta perspectiva, pelo questionamento, pela problematização, pela apresentação de dúvidas que orientam discussões e troca de informações no contexto de uma comunidade de aprendizagem colaborativa. Aprender é envolver-se na troca coletiva comunitária, contribuindo e recebendo, refletindo e pondo em funcionamento uma inteligência coletiva.

Para aplicar esse último modelo num curso on-line, é fundamental dispor, conforme Azevedo (idem), de recursos de comunicação de "muitos-para-muitos" que permita e facilite a interação entre pessoas. Essas ferramentas podem contribuir para dar um grande salto na organização de propostas de formação de professores por meio do ciberespaço. A disponibilização de material didático e a possibilidade de comunicação um-a-um não deixam de ser necessárias, mas adquirem, dentro desse modelo, um caráter complementar, assim como o rastreamento da navegação do professor no site e instrumentos para a aferição de informações assimiladas.

No espaço de comunicação aberto e em sinergia com todos os dispositivos de criação de informação, de gravação, de comunicação e de simulação, pela conexão mundial dos computadores, os professores de diferentes contextos culturais, geograficamente dispersos, podem acessar, a distância, recursos de um outro computador e fazer transferência de arquivos, consultar hiperdocumentos dentro de uma mesma rede, explorar e alimentar simultaneamente o conteúdo de um banco de dados, trocar mensagens por correio eletrônico, escrever e publicar, conforme Lévy (1999) "no maior canal de comunicação e suporte de memória da humanidade". Esses 
professores podem, ainda, optar por ser protagonistas passivos de um processo de comunicação de intercâmbio complexo.

Com essas ferramentas para educação on-line, disponíveis no mercado, se quisermos acompanhar os avanços e procurar responder às novas demandas postas pelas transformações pelas quais vêm passando nossa civilização nos últimos anos, em grande medida resultantes do avanço tecnológico, os nossos principais desafios na formação profissional de professores consiste justamente em desenvolver antes de tudo competências e habilidades para que aprendam a aperfeiçoar, constantemente, seus conhecimentos, uma vez que o conhecimento envelhece aceleradamente e a produção e circulação de novas informações é cada vez mais intensa na atualidade.

Preparar melhor o professor para a nossa sociedade significa valorizar mais a capacidade de atuar em redes colaborativas, optando por "coursewares" que ofereçam recursos para o trabalho coletivo e a interação entre pessoas de modo síncrono ou assíncrono, prevendo que os professores não só recebam informações, mas também tenham a possibilidade de descrever bem como de repensar suas concepções e ações durante o processo. Com isso, não é apenas a técnica de ensino que muda, incorporando uma nova tecnologia. Mais do que isso, são as ferramentas e concepções do ensino que têm de ser repensadas no sentido de que ocorra uma mutação antropológica, epistemológica e metodológica, conforme defendem Lévy, Maturana e Varela.

\section{FUNDAMENTOS TEÓRICOS NO DESENVOLVIMENTO DE PROFESSORES DE LÍNGUAS UTILIZANDO O CIBERESPAÇO}

A proposta de formação do professor de línguas aqui adotada segue o modelo holístico de Richter (Richter, 2004; Richter e Paz, 2004), que na versão atual engloba dois macrocomponentes: a) prática social, utilizando uma abordagem sistêmica da pesquisa-ação embasada nos preceitos de Kemmis \& McTaggart e Day; e b) emprego de gêneros textuais de desenvolvimento docente (diários, chats, etc,) trabalhados numa perspectiva discursiva segundo Bronckart e Liberalli, alternada e integradamente subjetiva (para um sujeito metacognoscente, ou seja, dotado de uma metaconsciência ainda emergente nesse nível) e intersubjetiva (para um sujeito transcognoscente, ou seja, dotado, no nível especificado, de uma consciência 
transcendente em relação à dicotomia observador-fenômeno). Ainda segundo esse modelo holístico, esses macrocomponentes funcionam basicamente em nível epistemológico, ou seja, fornecem o fundo teorético para a análise e interpretação dos dados obtidos do corpus gerado no programa específico de formação docente. Por sua vez, a obtenção dos dados relevantes a partir dos textos de docentes baseia-se no Paradigma Indiciário (Ginzburg, 1987; Eco e Sebeok,1991), que neste modelo responde pelo nível heurístico dos procedimentos investigativos.

\subsection{O PRIMEIRO MACROCOMPONENTE}

Com relação ao primeiro macrocomponente, a formação continuada consiste em uma prática social metódica, contextualizada e complexa que visa a desautomatizar uma cultura de ensinar e aprender alicerçada em teorias, valores, mitos introjetados e ultrapassados e tenta predispor o docente a seguir o caminho em que tenha a liberdade de se autodeterminar profissional e socialmente, respeitando as limitações do contexto, agindo conforme o desejo articulado às formas de representar a si mesmo e ao outro no papel social exercido (isto é, o imaginário compartilhado).

Ainda segundo o modelo holístico de Richter, uma formação profissional, quer inicial, quer em serviço, que privilegie a reflexão crítica, deve ser organizada sistemicamente, levando em conta as dimensões (que tornam-se progressiva e respectivamente mais profundas): epistêmica, alética, deôntica e axiológica da rede cognitivo-afetivocomportamental - se o objetivo principal é a mudança. Isto porque o professor, como todo ser humano, é dotado de modelos mentais estruturados em função de crenças, desejos, valores, intenções e condutas que o levam, por um lado, a desempenhar determinados papéis de forma consistente com sua cultura (D’Andrade,1987) e, por outro, a resistir fortemente (inclusive expressando de múltiplas maneiras essa resistência) à mudança desses esquemas comportamentais (Beck, 1997).

Já a partir da perspectiva de pesquisa-ação sistêmica de Leitch \& Day (2000), podemos dizer que, para ocorrerem tais mudanças desejáveis, é preciso, principalmente, que os aspectos emocionais e os valores do professor sejam trabalhados e transformados em uma comunidade de pares agregada em função de objetivos em comum. Desta forma, serão maiores as chances de este profissional perceber suas experiências de outra maneira que não aquela que automatizou (e que 
o determina inconscientemente), alterando assim valores, crenças e condutas simultaneamente e formando conceitos mais consistentes com a relação teoria-prática de seu contexto. Mesmo que a participação do docente não se demonstre tão ativa e espontânea no contexto de formação, mudanças incipientes podem se esboçar ainda que na forma de autoquestionamentos e predisposição para reformulações futuras.

Leitch \& Day sugerem que a pesquisa-ação sistêmica empregue, como suporte auxiliar (entre outros), ferramentas conceituais das psicoterapias. Quanto a este aspecto, cremos que os princípios teóricos e práticos da Terapia Cognitiva (TC), numa cuidadosa releitura e readequação ao contexto de formação docente, podem tornarse promissores quanto à quebra de resistências e conseqüentemente facilitação de mudanças de atitudes e condutas. Essa proposta de trabalho busca a reestruturação das crenças e sua funcionalização a partir da análise das estruturas cognitivas do paciente e de problemas decorrentes de aspectos disfuncionais destas. Entre outras técnicas, é utilizado o questionamento socrático aliado a protocolos de resolução de problemas, a fim de desafiar essas crenças disfuncionais que se tornaram rígidas e generalizadas.

Alguns princípios importantes dessa linha de trabalho assim se resumem:

1. Preocupação com o desenvolvimento contínuo do indivíduo e com seus problemas cognitivos. Conceituação das dificuldades, identificação do pensamento atual, comportamentos problemáticos e de fatores que influenciaram as percepções, assim como o levantamento de hipóteses sobre o desenvolvimento e padrões duradouros de interpretação distorcida dos indivíduos.

2. Relação de confiança, cordialidade, empatia, respeito entre os envolvidos como elementos essenciais para que se forme uma aliança de trabalho segura e promissora.

3. Ênfase no trabalho colaborativo e participativo, em que os envolvidos tenham a iniciativa de tomar decisões.

4. Orientação a metas e focalização em problemas, com monitoramento e avaliação constantes.

5. Educação do indivíduo para que possa, dentro do seu tempo e ritmo, ser seu próprio terapeuta, aprendendo a identificar, avaliar e responder a seus pensamentos e crenças disfuncionais, enfatizando a prevenção à recaída. 
6. Uso de diferentes estratégias cognitivas para mudar simultaneamente pensamento, humor e comportamento, de acordo com a especificidade dos casos e seus objetivos.

Conforme Beck (1997), o modo como as pessoas se sentem está associado ao modo como elas interpretam e pensam sobre uma situação. O comportamento dessas pessoas é, em grande parte, determinado por esquemas cognitivos parcialmente inconscientes e refratários a controle voluntário, que, acionados por representações de conhecimento mentalmente ativadas, sem a deliberação pessoal originam os pensamentos automáticos, que em geral são bastante rápidos e breves. Estes pensamentos estão ligados a fenômenos cognitivos mais duradouros que são as crenças.

Os entendimentos profundos, globais, rígidos e supergeneralizados, tidos pelo sujeito como verdades absolutas, formam as crenças centrais (e que, no modelo holístico, apresentam alguma conexão com o nível axiológico das representações do indivíduo). Estas constituem o nível mais fundamental das crenças e influenciam o desenvolvimento de uma classe intermediária de crenças que consiste em atitudes, regras e suposições, freqüentemente compensatórias e não articuladas (no mesmo modelo holístico, o nível deôntico). As crenças subjacentes das pessoas influenciam sua percepção, que é expressa por pensamentos automáticos específicos à situação. Esses pensamentos, por sua vez, manifestam-se através das emoções das pessoas, provocando reações e outras manifestações de conduta.

Embora a TC, como vem sendo utilizada na psicologia clínica, tenha se apresentado como uma abordagem propícia para provocar mudanças, na área de formação de professores de línguas, como mais uma vez queremos deixar claro, ela não é autoaplicável, haja vista sua aplicação originária e amplitude no tratamento de disfunções, bem como a forma cartesiana como agem os envolvidos no processo de terapia. Contudo, há características desta linha de trabalho que a aproximam da pesquisaação, abordagem de cunho social, mas indissociável da vida psíquica e compatível em formação de professores. Essa aproximação permite que, utilizando algumas de suas estratégias básicas aliadas à abordagem investigativa em discursos registrados em instrumentos adequados, crenças, sentimentos, saberes, esquemas, desejos, intenções, condutas sejam reconhecidos de forma holística, em um todo cognitivoafetivo-comportamental. Tais investigações podem ser conduzidas, como já 
mencionamos, via Paradigma Indiciário, formulando hipóteses explicativas a partir dos dados fornecidos nos registros, que poderão se confirmar ou não tendo em vista os demais aspectos qualitativos do contexto.

Leitch \& Day (idem) sugerem que nos cursos de formação de professores sejam conduzidas profundas reflexões abrangendo todas as dimensões do indivíduo e recomendam a implementação de um modelo de ação que percorra três instâncias: a racional, a emocional e o imaginário para orientar o desenvolvimento dos docentes, seguindo uma abordagem metodológica de reflexão na pesquisa-ação que tenha por base uma linha de ação centrada em fundamentos da psicologia ou da psicoterapia para incluir transformações.

De acordo com os mesmos autores, a prática reflexiva e a pesquisa-ação são consideradas dimensões críticas no desenvolvimento profissional de professores em que a reflexão facilita a mudança pessoal e profissional. Para eles, há três razões essenciais para se promover a prática reflexiva. A primeira se refere à natureza do ensino. Sem a avaliação constante dos conteúdos desenvolvidos, os docentes correm riscos de ficar presos a programas curriculares, tornando-se ultrapassados. A segunda razão aponta para o auto-conhecimento e para mudanças pessoais, em que uma análise de valores pessoais e teorias são realizadas. Por fim, a terceira é que a prática reflexiva pode levar o professor a perceber que ele é um agente profissional do conhecimento e não um objeto de simples implementação de teorias de "especialistas". Cabe ao docente aprender como manter-se em processo constante de desenvolvimento para poder estabelecer relações entre o contexto escolar e o mundo circundante e superar as resistências à mudança. Ele pode beneficiar-se da constatação de que a formação sem os instrumentos técnicos torna-se fragilizada e a aproximação produtiva do conhecimento procedural com o científico é indispensável para que na formação continuada não resultem meros "belos discursos" paralelamente ao imobilismo das condutas - mas genuínas transformações.

\subsection{O SEGUNDO MACROCOMPONENTE}

No segundo macro-componente, o trabalho reflexivo-crítico sobre gêneros da formação docente (chats, fóruns e diários, publicados, neste caso, em ambientes virtuais de aprendizagem), associado a abordagens cognitivas auxiliares e à pesquisa- 
ação sistêmica, empenha-se em desarticular automatismos conceituais (crenças disfuncionais) sobre aspectos básicos da cultura de ensinar-aprender línguas (destacamos aqui, por força de projeto em andamento, os de leitura e gramática) dentro de uma proposta de mudança envolvendo professores de línguas.

Para Gee (1999), discurso é tanto prática social quanto entidade cognitiva (construtora de mundos discursivos), que permite a interação situada de pessoas, possibilitando o reconhecimento de identidades e atividades sociais pertinentes ao contexto em que estão inseridas. Desta forma, por meio da análise do discurso de professores em processo de formação continuada, poderemos verificar como esses representam a si próprios e, também, ao outro, além de identificarmos suas crenças de ensinoaprendizagem de línguas e seus conceitos (entre os quais, leitura e gramática).

O professor, ao fazer parte de um grupo social, constrói crenças e conceitos, conscientes ou inconscientes, que se revelam na forma como ele lê, como se manifesta de forma oral ou por escrito, como orienta e propõe ações na sala de aula. Essas crenças podem ser construídas tanto em grupos acadêmicos quanto nos não acadêmicos, o que geraria perspectivas variadas na forma de entender-se o que é leitura e gramática.

Por exemplo, quanto aos conceitos de leitura, Coracini (1995) e Zappone (2001) revelam, no meio acadêmico, as várias concepções que norteiam as visões de leitura. Coracini identifica, sumariamente, três posturas teóricas relacionadas à concepção de leitura e classifica-as em: leitura como decodificação, leitura como interação entre leitor e o texto e leitura como um processo discursivo. Zappone sintetizou e classificou o tópico em quatro linhas teóricas básicas, quais sejam: a política-disgnóstica, a cognitivo-processual, a discursiva e a estruturalista. Já no que tange às diferentes visões possíveis de gramática, vale destacar as contribuições, aqui apenas mencionadas, de Possenti, Perini, Luft e Travaglia. Numa visão panorâmica, elas se desdobram em: normativa, descritiva, internalizada, implícita, explícita e reflexiva. A adoção de cada uma delas vai depender do contexto e do propósito de sua utilização - visto que o estudo da gramática em ambiente escolar jamais pode se deter na simples análise ou classificação de elementos lingüísticos; mais do que isso, deve empenhar-se em ser um instrumento da construção intersubjetiva de sentidos, com vistas ao objetivo maior do estudo de línguas, qual seja, a formação da competência comunicativa. 


\section{CONSIDERAÇÕES FINAIS}

Em síntese, uma proposta de formação continuada de professores de línguas, com enfoque na formação de conceitos da prática docente, deve estruturar-se na linha de práticas sociais reflexivas que vise a identificar os conceitos disfuncionais e a acompanhar possíveis transformações de crenças, conceitos, sentimentos, valores e condutas. Espera-se também que prime pelo desenvolvimento de habilidades e competências, prevendo a continuidade de estudos de modo autônomo em etapas posteriores. Por fim, o trabalho em rede não pode prescindir do embasamento em teorias condizentes com um paradigma holístico, considerando as dimensões epistêmica, alética, deôntica e axiológica do esquema cognitivo-afetivocomportamental.

\section{BIBLIOGRAFIA}

AZEVEDO, W. (2002) Paradigma atual de Educação a distância no Brasil.

Disponível em: <http://www.aquifolium.com.br/educacional/artigos/panoread.html> BECK, J. Terapia Cognitiva: teoria e prática. Porto Alegre: Artes Médicas, 1997. BURNS, A. Collaborative action research for English language teachers. Cambridge: Cambridge University Press, 1999.

CORACINI, M. J. Análise do discurso: em busca de uma metodologia. Revista D.E.L.T.A., v.2, n.1, 1991.

. 0 jogo discursivo na aula de leitura: língua materna e língua estrangeira. Campinas: Pontes, 1995.

D'ANDRADE, R. (1987). A folk model of mind. In: HOLLAND, D. \& QUINN, N.

Cultural Models in Language \& Thought. Cambridge: Cambridge University Press, 1995. p.112-148.

ECO, U. e SEBEOK, T.A. O signo de três. São Paulo: Perspectiva, 1991.

GEE, J. P. Social linguistics and literacies. London: The Falmer Press, 1999.

GINZBURG, C. O queijo e os vermes. São Paulo: Companhia das Letras, 1987. GÓMEZ, A. P. O pensamento prático do professor: a formação do professor como profissional reflexivo. In: NÓVOA, A. Os professores e a sua formação. 2 Ed., Portugal, Publicações Dom Quixote, Lda. 1995. 
KEMMIS, S. \& MCTAGGART, R. The action research planner. 3. ed. Geelong, Victoria: Deakin University Press, 1988.

LEITCH, R \& DAY, C. (2000) Action Research and Reflective Practice: towards a holistic view. disponível em < http://www.triangle.co.uk/ear/>

LÉVY, P. As tecnologias da inteligência; Tradução de Carlos Irineu da Costa. RJ: Ed. 34, 1993.

A inteligência coletiva: por uma antropologia do ciberespaço. São Paulo: Loyola, 1998.

Cibercultura. Trad. Carlos Irineu da Costa. SP: Editora 34, 1999.

LUFT, C. P. Língua \& liberdade: por uma nova concepção da língua materna. 7. ed. Porto Alegre: L\&PM, 1985.

MAGDALENA, B. C. \& COSTA, I. E. T. A lógica dos contextos e o ciberespaço. Pátio: Revista Pedagógica. Ano VII, no 26. Maio-julho /2003. Ed. Artes Médicas Sul Ltda.

MATURANA, H., VARELA, F. A árvore do conhecimento: as bases biológicas do entendimento humano. São Paulo: PSY, 1995.

PERINI, M. A. Gramática descritiva do português. S. P.: Ática, 1998. Sofrendo a Gramática. São Paulo: Ática, 2000.

POSSENTI, S. Discurso, estilo e subjetividade. S. P.: Martins Fontes, 1993. Letras, 2000.

Por que (não) ensinar gramática na escola. Campinas: Mercado de

RICHTER, M.G. Formação holística docente a distância. Projeto de Pesquisa. GAP-CAL, UFSM, 2004 (inédito).

RICHTER, M.G. e PAZ, D.M.S. Horizontalização de superação das hierarquias e das diferenças em um diário de uma acadêmica em formação. II SIGET -

Simpósio nacional de Estudo dos Gêneros Textuais. Paraná: União da Vitória, 2004.

TRAVAGLIA, L.C. Gramática e interação: uma proposta para o ensino de gramática no $1^{\circ}$ e $2^{\circ}$ graus. 4. ed. SP.: Cortez, 1998.

VYGOTSKY, L.S. Pensamento e linguagem. S. P.: Martins Fontes, 1998.

ZAPPONE, M. H. Y. (2001) Práticas de leitura na escola. Tese de doutor em Teoria Literária do Instituto de Estudos da Linguagem da Universidade Estadual de Campinas. Disponível em <www.unicamp.briel/memoria.index.htm >. Acesso em 01/07/2003. 